\title{
Reseña de Cabanillas Cárdenas, Carlos F. (ed.), Sujetos coloniales: escritura, identidad y negociación en Hispanoamérica (siglos XVI-XVIII), New York, Instituto de Estudios Auriseculares (IDEA), 2017, 283 pp. ISBN: 978-1-938795-32-9
}

\section{Daniele Arciello}

Universidad de León

ESPAÑA

arciellod@gmail.com

[Hipogrifo, (issn: 2328-1308), 6.1, 2018, pp. 707-713]

Recibido: 04-01-2018 / Aceptado: 09-02-2018

DOI: http://dx.doi.org/10.13035/H.2018.06.01.47

En el seno del proyecto de investigación «Encuentros y transferencias culturales en la literatura latinoamericana colonial (siglos XV-XVIII)» de la UIT Universidad Ártica de Noruega, en Troms $\varnothing$, se celebraron dos seminarios - Conflictos coloniales: indios, criollos y peninsulares en textos de la Hispanoamérica colonial y Sujetos coloniales. Homogeneización, negociación y subversión en los textos hispanoamericanos (siglos XVI-XVIII) - en los que se presentaron una serie de innovadores trabajos relacionados con este campo de investigación, y que componen el libro que ahora se reseña. Numerosos especialistas han entregado sus esfuerzos al examen de un tema que indudablemente sigue deparando cuestiones críticas de mucho interés, originando debates de notable relevancia. Sus estudios arrojan un halo de luz sobre la heterogénea realidad social de los territorios americanos: el sujeto coIonial, argumento medular de la monografía, es paradigma del complejo tejido de relaciones que va urdiéndose a medida que se multiplican las interacciones entre oriundos y extranjeros durante la época virreinal. Cada autor nos guía en un viaje hacia el (re)descubrimiento de estas etapas históricas y culturales inscritas en el macro-fenómeno de la convivencia, forzosa o no, que ya a partir del siglo XV ha caracterizado al mundo hispanoamericano. 
La lectura se abre con Rolena Adorno y su «Carlos de Sigüenza y Góngora y las antigüedades mexicanas». Al ofrecernos un análisis biográfico del cortesano criollo desde un sugestivo punto de vista, su estudio recalca cómo la mirada hacia el pasado mexicano de don Carlos tomaba derroteros teleológicos distintos, es decir, con independencia de la actitud de eruditos coevos. Ya no fue una substitución de la mitología precolombina en beneficio de la cristiana, sino que se aspiraba a un decoro académico que permitiera el asentamiento de la noción de patria. Tras aclarar que patria para el polímata mexicano fue herramienta intelectual eficaz contra el olvido, Adorno afirma que Teatro de virtudes políticas representaba cabalmente la ideología de Sigüenza. Compuesta para homenajear al nuevo virrey, don Tomás Manrique de la Cerda, exaltaba sus dotes creando un paralelismo con los antiguos soberanos aztecas. En eso, pues, estribaba la originalidad de la obra: lo crucial que para don Carlos era, en palabras de Adorno, «dignificar el pasado mexicano como algo histórico» (p. 15). De ahí que el eje temático no se fundara en la glorificación de hazañas militares, sino en el ajuar de facultades de los monarcas mexicanos que precedían al vicesoberano. A través de la potencia visual de sus imágenes, que reemplazaban los cálculos astronómicos y matemáticos en otras obras de don Carlos, fue Teatro de virtudes políticas la que más atinadamente consiguió su finalidad. Adorno acierta en vislumbrar la genialidad de un sabio que pudo primar por encima de otros, incluso en un género artístico cuyos aspectos intrínsecos perduraban desde los tiempos antiguos. Extraña, pues, que en la extensa bibliografía del artículo no se haga mención de un ensayo - La prosa de Sigüenza y Góngora y la formación de la conciencia criolla mexicana (1996), de Antonio Lorente Medina-, que de forma análoga incide en la estructura de Teatro de virtudes políticas y en su repercusión social.

De índole diferente, pero no por ello menos significativa, es la postura que Ignacio Arellano adopta en «Subversiones (o no) en la poesía colonial, y la construcción crítica al margen del texto». Su artículo responde a la impelente exigencia de insistir en la carencia, en muchas investigaciones actuales, de una metodología hermenéutica adecuada, que él juzga imprescindible a la hora de aproximarse a textos de periodos históricos no contemporáneos. Lo que mayoritariamente se emplea en las últimas décadas es un procedimiento que a menudo desemboca en comentarios anacrónicos y fantasiosos en detrimento de un escrutinio imparcial y que, por ende, necesita de un replanteamiento radical falto de prejuicios e interpretaciones poco pertinentes. Aquello que se torna indispensable para el objetivo anteriormente expuesto es lo que para Arellano es la «competencia filológica» (p. 36). Con el fin de avalar su tesis expone algunos de los ejemplos más llamativos al respecto; de los tópicos más debatidos sobresale la cuestión criolla, en particular la supuesta crítica al régimen metropolitano, que llevarían a cabo quienes formaban parte de la flor de los pensadores americanos. Si bien fue inequivocablemente auténtico el deseo de reivindicar el renombre de las letras en tierras indias, sería arduo localizar en esos textos una invectiva explicita dirigida a la Corona. La labor analítica reciente del corpus de Juan del Valle y Caviedes sintetiza a la perfección el contraste entre los nuevos enfoques y lo que realmente pretendía el poeta. Lo burlesco, imbuido en sus versos, induce a creer que se tratase de una filípica, cuya función principal 
hubiera sido hostilizar a la administración de los españoles en los virreinatos. Sin embargo, Arellano pondera que sus ataques carecían de seriedad: correspondían a una tradición bien arraigada en la literatura áurea de la que Caviedes era gran conocedor y admirador, conque en absoluto cruzaba los límites de la sátira convencional. Con argucia y un adarme de sutil ironía el crítico enumera otros posicionamientos desacertados, tales como las búsquedas a menudo injustificadas de matices feministas o de rebelión y subversión. Se hace necesaria la rigurosidad del método filológico que elegir, dado que «difícil será valorar con sensatez un texto que no se ha comprendido» (p. 54).

En el tercer artículo se aprecia ya desde el título -«El sujeto colonial mulato en la poesía de Juan del Valle y Caviedes» - la vertiente innovadora aquí desarrollada, en sintonía con el genio limeño del que brotaron obras poéticas señeras. Del acervo de personajes que poblaban el corpus de Caviedes, el autor del estudio, Carlos Cabanillas, pretende destacar la figura del 'mulato', en particular la de los dos médicos Pedro de Utrilla, padre e hijo. Cabanillas describe el contexto social en el que hombres que llevaban sangre negra en sus venas se unían con mujeres indias y, al margen de sufrir la denominación de zambos o mulatos, procuraban mejorar su condición frente al estatismo de la casta a ellos impuesta. Los datos históricos que se proporcionan, además de favorecer la comprensión de la escritura del célebre poeta, introducen las reflexiones finales que ilustran los comentarios de Juan del Valle, cuya mordacidad desacreditaba las acciones de avance social perpetradas por Utrilla joven, hijo de un esclavo. La asociación cromática entre el legado infamante y el color de la piel de su prole avaloraba, según el poeta, la urgencia de mostrar mayor humildad. En conclusión, cabe dilucidar la controversia sobre los versos satíricos en la óptica de una reutilización del patrón metropolitano en una realidad geográfico-social contundentemente distinta.

Es muy frecuente caer en la tentación de destinar un manuscrito elaborado en el Ultramar a rubros de categorías de procedencia europea, o que ocurra lo contrario y se atribuyan erróneamente a exponentes de comunidades indias. Su ardua colocación causa perplejidades desprovistas de una respuesta concluyente. A la vista de ello, Marguerite Cattan en «La retórica clásica en la Instrucción de Titu Cusi Yupanqui» hace hincapié en el talante retórico de Instrucción al Licenciado don Lope García de Castro; aquilatar el empleo de un recurso de origen clásico es clave para avalar la hipótesis de una autoría no americana. Es apropiada, pues, la realización de un cotejo entre las partes que componían el parlamento retórico y el testimonio de Yupanqui, que ofrecía su versión del encuentro con Atahualpa y los españoles. Justamente es la inspiración modélica lo que induce a Cattan a poner en tela de juicio hasta qué punto la relación hubiera sido manipulada. Es que el cometido de la traducción fue concedido a fray Marcos García, pero el tono persuasivo, el pathos con el que el cacique defendía sus aseveraciones, hace presuponer que Marcos no se limitara a convertir el texto en documento comprensible para los conquistadores, sino que lo amoldaría tajantemente ajustándolo a sus pretensiones ético-literarias. Es meritoria, pues, la propuesta de Cattan para una obra que aún no deja de sorprender por lo que puede yacer soslayado en un contenido de engañosa adscripción. 
«Los indígenas en la obra de Fernández de Lizardi: justicia, caridad y devoción» nos sitúa en la época del Pensador Mexicano, cuya obra edificó un puente entre virreinatos y época de la independencia. La tarea de realzar la visión filoindia de Lizardi corre a cargo de Beatriz de Alba-Koch; apodícticamente no se pueden eludir las aportaciones socio-filosóficas del novelista mexicano deducibles de su prolífica producción ensayística. El acopio de noticias históricas que la autora procesa nos ayuda para la comprensión cabal de cómo Fernández de Lizardi concebía el sujeto indígena. Al dividir el trabajo en tres focos (justicia, caridad y devoción), Alba-Koch bordea la temática de forma sugerente. De sus ponderaciones se colige el elogio de los nativos, imposible de aceptar como genuino sin matizaciones esmeradas. Ejemplo de ello es la reducción a meros arquetipos, haciendo caso omiso de las etnias que jalonaban un componente social tan variado. Es posible que Lizardi ciñera su pensamiento al ámbito ilustrado, y que de esta forma encauzara sus postulados en una ideología canónica. No causaría asombro, pues, la conformidad con el rechazo estereotipado de un avance cultural del indígena virreinal: es el oriundo pre-conquista quien personificaba el ajuar de virtudes del que tomar inspiración para la nueva república. Predilección similar sentía por lo caritativo y devoto que los indígenas demostraban ser con los blancos, si bien nunca llegando a constituir integración y mestizaje plenamente realizados. Para concluir, Lizardi propugnaba la honestidad de los autóctonos en un triunfo de la mentalidad a la sazón: su inclinación protectora de ningún modo presupuso una posición efectiva igualitaria con el "otro". Como bien apunta Alba-Koch, el acto de espigar la bibliografía lizardiana, lejos de ofrecernos un cuadro fidedigno del panorama social decimonónico, adquiere el designio de poner al descubierto la filosofía de este gran intelectual.

De tintes polemológicos son las consideraciones que Miguel Donoso Rodríguez formula en «Sobre invenciones de guerra dañosas en La historia de todas las cosas que han acaecido en el reino de Chile (1575), de Alonso de Góngora Marmolejo». La Historia resulta ser un documento valioso de cara a la indomable resistencia de los araucanos. De los folios de Marmolejo se infiere la ausencia de todo adorno estilístico en aras de mayor franqueza, a la zaga de la verdad sobre los hechos sobrevenidos. Del enfrentamiento entre el ejército peninsular y el conjunto de tribus de la zona del Biobío emergió el carisma de Lautaro. Este líder consiguió «desmitificar en forma pública la idea casi sobrenatural que de los peninsulares tenían los indígenas, desnudando su mortalidad y la precariedad, debido a su escaso número, de su dominación» (p. 121). Su excepcional valentía fue aliciente decisivo en el levantamiento, pero otros factores también determinaron la debacle española. Conocimiento excelente del terreno, provisiones inagotables de agua para abastecer a las tropas, arsenal renovado con invenciones revolucionarias, todo auspició la reacción obstinada de un pueblo orgulloso de su libertad.

Sabido es que las lecturas previas configuran la manera de relatar nuevas experiencias vividas en cronotopos alejados de los territorios patrios. Hasta pueden prevalecer en menoscabo de indagaciones directas, si la corriente estética en la que se engloba el escrito se remonta a los siglos anteriores al empirismo ilustrado. Es el caso de los comentaristas europeos en tierras ultramarinas, como bien anota José Luis Gastañaga Ponce de León en «"El villano del Danubio" en los Andes: sujetos 
coloniales en el Libro de la vida y costumbres de Alonso Enríquez de Guzmán». El episodio novelado primero en el Libro áureo de Marco Aurelio, y posteriormente en el Relox de príncipes por fray Antonio de Guevara, obtuvo un éxito tan remarcable que dejó huella en la pluma de Fernández de Oviedo, Pedro Cieza de León y Alonso Enríquez de Guzmán. Gastañaga recapitula exhaustivamente lo que Guevara -al denigrar la moralidad en el imperio romano comparándola con la codicia de los españoles en las Indias - condenaba, es decir, no el hecho en sí de la conquista, sino los excesos que conllevaba. Asimismo, ahonda en los motivos diegéticos con los que Enríquez de Guzmán elaboró el pleito de un aborigen, que en cierta medida se asemejaba a la figura del rústico en la obra de Guevara. Claro está que a pesar de ser testigo presencial de un discurso cuya elocuencia en pro de los derechos de los aborígenes impresionó a la platea, su formación de cortesano español condicionó su opinión, produciendo un directo parangón con el aldeano danubiano. Lo que fácilmente se conjetura es la desenvoltura mediante la que se tipificaba toda muestra discursiva que evocaba modelos literarios europeos, acción máxime acentuada por venir comúnmente de un contexto nobiliario ajeno a la situación en que se escuchaban las voces de la otredad.

En el escenario andino, los conocimientos literarios no fueron materia desconocida tampoco por los indios, al entrar en contacto con la producción libresca - de los colonizadores primero, de los creyentes después - en Perú. Si quisiéramos buscar un acicate vital en el procedimiento formativo indígena, nos percataríamos enseguida de cómo la importación de obras europeas abrió la senda hacia este formidable evento. Es lo que subraya Pedro M. Guibovich en «Indios y libros en el virreinato del Perú». La barrera cultural a la postre no fue óbice para la distribución capilar de publicaciones foráneas en la élite india, especialmente cuando esta se adhería al propósito del clero y de los virreyes de adoctrinarla y evangelizarla. Con todo, la enjundia de los debates gravitaba en torno a dos preocupaciones: el riesgo de proveerles, a los que fueron unívocamente instruidos, armas jurídicas que se pudieran esgrimir consultando impresos no religiosos; el peligro de pervertir su mente con relatos amenos o viciosos. No se podía en efecto pasar por alto la cantidad de escritos no devocionales que circulaban en aquel entonces. Adicionalmente, Lima fue punto neurálgico del mercado de las letras, convirtiéndose en promotora de la difusión cultural peruana: alcanzó aun a los rincones más periféricos de los dominios del Imperio, y dio lugar a un discernimiento en los campos jurídicos y sociales admirable; Guibovich aborda lúcida y puntualmente esta complejidad, concerniente al macromundo de la imprenta virreinal.

Con un exordio de raigambre filosófica, Esperanza López Parada -en «La genealogía como dispositivo de identidad: un príncipe melancólico en la línea sucesoria» - tematiza una práctica usual entre los biógrafos transatlánticos, que, para detectar los rasgos psicológicos aptos para corroborar sus argumentaciones, tamizaban el material genealógico que poseían sobre los miembros de sangre real. Los Comentarios reales de los Incas del Inca Garcilaso de la Vega fueron emblema de una praxis que adulteraba la recepción de las vicisitudes, en este caso, de un príncipe, dando un vuelco a la valoración de sus cualidades. Al fin y al cabo, «este ejercicio de proyección alterada [...] puede ponerse en marcha sólo desde la movi- 
lidad recreada y porosa de las gestiones genealógicas, nunca desde la férrea disciplina o la insobornable cronología de las formulaciones genésicas» (p. 208). A raíz del mecanismo ficcional que Garcilaso activó, sirviéndose de la melancolía como espejo de una personalidad ingeniosa y competente - por vía contraria de las teorías europeas que denigraban al hombre taciturno-, se ennoblecía una modalidad gubernamental de matriz incaica.

Sería inapropiado cifrar la habilidad de un escritor en su talento innato, elidiendo el rol capital que desempeña un aprendizaje pedagógico provechoso. José A. Rodríguez Garrido ha querido llamar la atención sobre un asunto en concreto, es decir, la educación del Lunarejo en «Espinosa Medrano, dramaturgo y colegial del seminario de San Antonio Abad de Cuzco». Al parecer, su consagración al cultivo de piezas escénicas se debió a lo que le fue enseñado en un colegio jesuita: si filtráramos el aporte original de Medrano en lo que hasta la fecha se conoce de su corpus teatral (autos sacramentales en quechua, comedias marianas y un drama), nos cercioraríamos de las contribuciones aleccionadoras escolásticas, que el seminario brindaba a sus alumnos. A esto se añade el objeto primordial de dichas representaciones: otorgarle a la institución una reputación tal que le agilizara el reconocimiento como universidad de pleno derecho. Rodríguez Garrido no duda en poner énfasis en el enlace del Lunarejo con la escuela cuzqueña.

Un resorte narrativo cardinal como fue la descripción de hundimientos de barcos en aguas insidiosas, por las que navegaban los exploradores de la Edad Moderna, dio pábulo a una tipología per sé de diarios, periplos e itinerarios, que recogían los hallazgos más portentosos y expandían los horizontes espaciales y mentales de los destinatarios. De puntualizar la trayectoria relativa a los vectores fundantes de esta fenomenología se encarga Gilse Selnes en «El sujeto del naufragio: hombres, animales y caníbales en los relatos de náufragos coloniales». En el recorrido aquí esbozado de la evolución semántica del término náufrago se esclarece la significación metafórica de la palabra. Amén de observar cómo el orden jerárquico del navío sorprendentemente hacía de contrapunto al caos que el mar borrascoso generaba, Selnes contempla la culpabilidad que antiguamente se les imputaba a los que quebraban el equilibrio natural de las cosas, al zarpar hacia lo incógnito abandonando el propio hogar y, especialmente, en pos de riquezas soñadas. La avidez excitaba el afán de viajar. En una dimensión de marginación, el náufrago efectuaba un recuento de peripecias que involucraban a piratas y caníbales, sus enemigos jurados, y que encarnaban la amenaza central a la salvaguardia colonial. Por añadidura, la religión desempeñaba un papel fundamental a la hora de enfatizar la peligrosidad de grupos piráticos y antropofágicos: el impulso famélico se asociaba a rituales litúrgicos, y la transustanciación, en el caso de los católicos, a la antropofagia. Los Naufragios de Núñez Cabeza de Vaca e Infortunios de Alonso Ramírez atestiguaban en más de una ocasión la voluntad de discriminar a entidades reputadas malignas. De igual modo la parte fabulada cobraba importancia en las biografías, bien entendido que la invención expresaba lo inexplicable con el auxilio de un vocablo puramente barroco: lo admirable. Imaginación y veracidad se compaginaban en la plasmación de un patrón perteneciente a lo catastrófico. 
Leonor M. Taiano Campoverde en «Casta, etnia y fe en Infortunios de Alonso Ramírez» retoma una controversia sobre la que ampliamente debatió en su tesis doctoral -Entre mecenazgo y piratería. Una recontextualización histórica e ideológica de Infortunios de Alonso Ramírez-, pero esta vez siguiendo otras directrices, que convergen en los problemas legales, hereditarios y comerciales que vejaban a la colectividad española y, por consiguiente, hispanoamericana. Taiano aventura la hipótesis de que el marinero portorriqueño, de acuerdo con los dictámenes de la regencia novohispana, se encaró con trabas no únicamente mercantiles, sino más bien dinásticas: el dogma de la limpieza de sangre perjudicaba a la obtención y mantenimiento de un botín de guerra, prescindiendo de las circunstancias. Por tanto, la voz de Ramírez supeditaba la de Sigüenza, en tanto en cuanto hacía falta refutar su presunto estatus de cristiano nuevo. El caballo de batalla de su defensa fue reincidir en la inhumanidad de los ingleses y en la falta de fervor espiritual de la tripulación que le asignaron, y contraponer dichas inmoralidades a su piedad. Aunque se haya reiteradamente argüido acerca de la sinceridad de Alonso y de la intervención del docto mexicano -incluso en las páginas del presente monográfico-, aquí novedosamente la fisionomía de los personajes se vuelve instrumento de persuasión esencial.

El ojo crítico de una lumbrera, al ventilar dilemas históricos y existenciales, siempre actúa como catalizador de procesos reflexivos, invitando a recapacitar sobre acontecimientos pretéritos, y sacando deducciones oportunas. Carmela Zanelli Velásquez, en «Re-escritura y refundación histórica: los casos de Cajamarca y el cerco del Cuzco bajo la mirada de Garcilaso en la segunda parte de los Comentarios reales», reanuda este axioma, y nos recuerda que el Inca Garcilaso de la Vega perseveró en reconsiderar el altercado de Cajamarca, para revestirlo de un aura positiva. El natural de Cuzco fue renuente a consentir que Atahualpa y su séquito fueran tildados de violentos, inciviles y heréticos, ya que fue todo un malentendido. De la misma suerte que Cattan, Zanelli Velásquez propone dar otra vuelta de tuerca al accidente diplomático con el prestigio de los Comentarios garcilasianos. Análogamente, la insurrección de Manco Inca fracasó - con arreglo a la suposición de Garcilaso- no por la conducta pecaminosa de los rebeldes, sino por los prodigios místicos a los que nadie pudiera hacer frente: se patentiza que toda crónica queda sometida, en última instancia, al arbitrio del historiador.

En conclusión, Sujetos coloniales es un producto de gran calado teórico, en el que se elucidan enigmas filológicos y se desmiente una caterva de clichés y falsedades, coadyuvando a la comprensión de los moldes genéricos que marcaron los discursos de las Américas prerrevolucionarias. La validez de una cuidadosa exegesis textual se conjuga con el primor que estos expertos filólogos han exhibido en trabajos indisputablemente interesantes; los solventes ensayos han hecho que las investigaciones actuales sean deudoras de lo que se ha examinado en este trayecto plurisecular de la literatura hispanoamericana. 